\title{
Memory Retrieval Requires Ongoing Protein Synthesis and NMDA Receptor Activity-Mediated AMPA Receptor Trafficking
}

\author{
Joëlle Lopez, Karine Gamache, Rilla Schneider, and Karim Nader \\ Department of Psychology, McGill University, Montreal, Quebec H3A 1B1, Canada
}

\begin{abstract}
Whereas consolidation and reconsolidation are considered dynamic processes requiring protein synthesis, memory retrieval has long been considered a passive readout of previously established plasticity. However, previous findings suggest that memory retrieval may be more dynamic than previously thought. This study therefore aimed at investigating the molecular mechanisms underlying memory retrieval in the rat. Infusion of protein synthesis inhibitors (rapamycin or anisomycin) in the amygdala $10 \mathrm{~min}$ before memory retrieval transiently impaired auditory fear memory expression, suggesting ongoing protein synthesis is required to enable memory retrieval. We then investigated the role of protein synthesis in NMDA receptor activity-mediated AMPA receptor trafficking. Coinfusion of an NMDA receptor antagonist (ifenprodil) or infusion of an AMPA receptor endocytosis inhibitor $\left(\mathrm{GluA}_{3 \mathrm{Y}}\right)$ before rapamycin prevented this memory impairment. Furthermore, rapamycin transiently decreased GluA1 levels at the postsynaptic density (PSD), but did not affect extrasynaptic sites. This effect at the PSD was prevented by an infusion of $\mathrm{GluA}_{3 \mathrm{Y}}$ before rapamycin. Together, these data show that ongoing protein synthesis is required before memory retrieval is engaged, and suggest that this protein synthesis may be involved in the NMDAR activity-mediated trafficking of AMPA receptors that takes place during memory retrieval.
\end{abstract}

Key words: AMPAR trafficking; fear conditioning; memory; protein synthesis; rat; retrieval

\section{Introduction}

Numerous studies have shown how dynamic the mechanisms mediating memory can be. Indeed, molecular mechanisms underlying acquisition, consolidation, and reconsolidation have been the focus of intense research (Kandel, 2001). Memory retrieval, defined here as accessing and expressing a memory trace in response to a conditioned stimulus (CS), has attracted less attention because it was believed to be only a passive readout of stored plasticity in the synapses induced by learning and consolidation (Davis and Squire, 1984; Kandel, 2001).

Currently, evidence suggests that consolidation and reconsolidation require de novo protein synthesis. Indeed, studies using protein synthesis inhibitors (PSIs) before or after training, or after reactivation, have shown long-term memory impairments (Berman et al., 1978; Davis and Squire, 1984; Castellucci et al., 1989). The different stages of learning and memory activate NMDA receptors (NMDARs), increasing intracellular calcium (Martin et al., 2000) and bringing a change in intracellular signaling pathways, leading to insertion of GluA1-containing AMPA

\footnotetext{
Received Feb. 21, 2014; revised Dec. 15, 2014; accepted Dec. 29, 2014.

Author contributions: J.L. and K.N. designed research; J.L., K.G., and R.S. performed research; J.L. analyzed data; J.L., K.G., and K.N. wrote the paper.

This research was supported by Canadian Institutes of Health Research Grant MOP-93540. We thank Yu-Tian Wang for providing $\mathrm{GluA2}_{3 \text {, }}$, Wayne Sossyn and Todd Sacktor for their comments on this manuscript, and S. Bors and $G$. Penny for their assistance in animal care.

Correspondence should be addressed to Dr. Joëlle Lopez, Department of Psychology, McGill University, 1205 Docteur Penfield Avenue, Montreal, Quebec H3A 1B1, Canada. E-mail: joelle.lopez@douglas.mcgill.ca.

DOI:10.1523/JNEUROSCI.0735-14.2015

Copyright $\odot 2015$ the authors $\quad 0270-6474 / 15 / 352465-11 \$ 15.00 / 0$
}

receptors (AMPARs) at the synapses within seconds (Choquet, 2010). These AMPARs are then replaced by GluA2-containing AMPARs to maintain memory over time (Malinow and Malenka, 2002).

Studies now show that memory retrieval may not be as passive a process as traditionally believed, and several authors have suggested it could share similar mechanisms with other memory processes (Szapiro et al., 2000; Abel and Lattal, 2001; Hall et al., 2001). Indeed, proteins associated with consolidation have been implicated in memory retrieval (Szapiro et al., 2002; Murchison et al., 2004), as well as metabotropic glutamate receptors and AMPARs (Riedel et al., 1999; Szapiro et al., 2000). Studies have also shown that GluA1-containing AMPAR postsynaptic insertion is necessary for auditory fear conditioning (Rumpel et al., 2005) and that AMPAR activation in the amygdala during memory retrieval is necessary for expression of the conditioned response (Nader, 2003; Ben Mamou et al., 2006). NMDARs, however, do not seem to be critical for memory retrieval (Steele and Morris, 1999; Abel and Lattal, 2001). Nonetheless, previous work demonstrated that NMDAR activation in the amygdala is necessary to destabilize an auditory fear memory (Ben Mamou et al., 2006). This suggests that NMDAR activity-mediated AMPAR trafficking could take place during memory retrieval.

Nevertheless, no previous study has directly investigated the necessity of protein synthesis for memory retrieval. Consequently, this study was specifically designed to address this question in auditory fear conditioning in rats, by infusing PSIs directly into the amygdala just before memory retrieval. The role of 
NMDAR activity-mediated AMPAR trafficking in memory retrieval was also assessed. We hypothesized that if protein synthesis is specifically crucial for memory retrieval, without affecting memory storage, a transient memory impairment would be observed after protein synthesis inhibition. We also postulated that if protein synthesis was involved in NMDAR activity-mediated AMPAR trafficking, PSIs would affect levels of AMPARs at the postsynaptic density (PSD). Results show that, as for consolidation and reconsolidation, protein synthesis is required to enable memory retrieval. Moreover, we show that this ongoing protein synthesis is necessary to maintain stable GluA1 levels at the PSD.

\section{Materials and Methods}

Animals. Male Sprague Dawley rats (275-300 g at arrival; Charles River) were housed in pairs in plastic cages with ad libitum access to food and water and maintained on a $12 \mathrm{~h}$ light/dark cycle (lights on at 7:00 A.M.). All procedures were approved by McGill's Animal Care Committee and complied with the Canadian Council on Animal Care guidelines.

Surgery. The rats were anesthetized with a mixture of ketamine (50 $\mathrm{mg} / \mathrm{ml})$, xylazine $(3 \mathrm{mg} / \mathrm{ml})$, and Dexdomitor $(0.175 \mathrm{mg} / \mathrm{ml})$ injected intraperitoneally. Analgesic treatment was administered subcutaneously before surgery (carprofen; $5 \mathrm{mg} / \mathrm{ml}$ ). Stainless-steel 22 gauge cannulae were bilaterally implanted in the amygdala (AP, -3.0 from Bregma; $\mathrm{ML},+/-5.3$ from the midline; DV, -8.0 from the skull surface). The cannulae were kept in place by dental cement tightly fixed to the skull with three stainless-steel screws. Obturators were then inserted into the cannulae to prevent blockage. An intraperitoneal injection of Antisedan $(0.5 \mathrm{mg} / \mathrm{ml})$ was administered after surgery to reverse the anesthesia, and the animals were placed in individual cages on heating pads until they woke up. The rats were then monitored daily during a 1 week recovery period, before the beginning of the behavioral study.

Drug infusions. Anisomycin (125 $\mu \mathrm{g} / \mu \mathrm{l}$; Sigma-Aldrich) was dissolved in equimolar $\mathrm{HCl}$ and saline, and rapamycin ( $1 \mu \mathrm{g} / \mu \mathrm{l}$; LC Laboratories) was dissolved in $80 \%$ DMSO solution. Ifenprodil $(2 \mu \mathrm{g} / \mu \mathrm{l}$; SigmaAldrich) was dissolved in sterile saline $(0.9 \% \mathrm{NaCl})$, and the ifenprodil/ rapamycin mixture was dissolved in $80 \%$ DMSO. GluA2 ${ }_{3 Y}$ [TAT(4757)- ${ }^{869}{ }^{\text {YKEGYNVYG }}{ }^{877} ; 15$ pmol] and Scr-GluR2 ${ }_{3 Y}$ [TAT(47-57)AKEGANVAG] were dissolved in PBS, $\mathrm{pH}$ 7.4. Drugs were infused bilaterally into the amygdala using 23 gauge injectors connected to Hamilton syringes via a 20 gauge plastic tube. All drug dilutions were adjusted so that a total volume of $0.5 \mu \mathrm{l}$ per side was infused by a microinfusion pump (KD Scientific; model 780220) at a rate of $0.25 \mu \mathrm{l} / \mathrm{min}$. Injectors were left in place for an additional minute to ensure proper drug diffusion. All drugs were infused $10 \mathrm{~min}$ before memory retrieval, except for GluA2 $2_{3 \mathrm{Y}}$, infused $1 \mathrm{~h}$ before memory retrieval, as done in a previous study (Migues et al., 2010).

Behavioral procedures. Rats were habituated to Context A for 15 min on Day 1 and Day 2. Context A was brightly lit and consisted of Plexiglas conditioning boxes enclosed in soundproof chambers $(30.5 \times 24.1 \times$ $21.0 \mathrm{~cm}$; Med Associates). The boxes each had black and white-striped front and back walls and rounded white plastic walls on the sides, as well as a white plastic floor. Peppermint-scented water was sprayed on the floor and the walls of the boxes. On Day 3, the rats were trained in Context $\mathrm{B}$, where they received five pairings of a tone $(20 \mathrm{~s}, 5 \mathrm{kHz}, 75 \mathrm{~dB})$ coterminating with a footshock $(1 \mathrm{~s}, 1.1 \mathrm{~mA})$ over a $15 \mathrm{~min}$ period. The first tone was presented $2 \mathrm{~min}$ after the rats were placed inside the boxes. After the last pairing, rats remained in the boxes for another $30 \mathrm{~s}$ before being returned to their home cages. For the rats to differentiate between the training and testing contexts, Context $\mathrm{B}$ consisted of a dimly lit room with transparent Plexiglas conditioning boxes, also enclosed in soundproofed chambers $(30 \times 25 \times 30 \mathrm{~cm}$; Coulbourn Instruments). A stainless-steel grid floor provided the shocks. A fan was on as background noise, and vanilla-scented water was sprayed on the boxes' walls. On Day 4 , animals were infused and then tested for long-term memory retention in Context A. After $2 \mathrm{~min}$ in the boxes, the rats were exposed to a single $30 \mathrm{~s}$ tone (the same as during training) and remained in the boxes for another $30 \mathrm{~s}$. Three hours later, rats were subjected to a second retrieval test, with no prior drug infusion. Digital cameras recorded the animals'
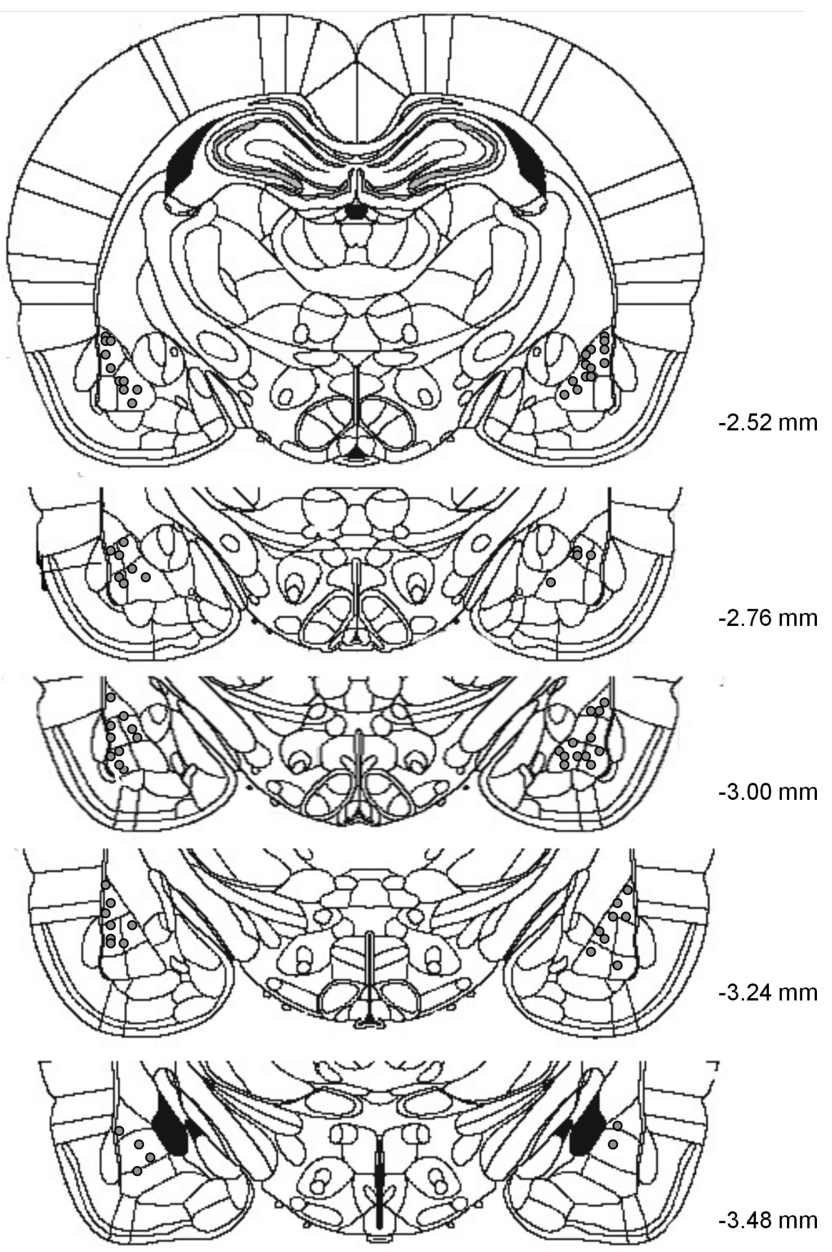

Figure 1. Schematic representation of representative cannula placements in the amygdala. The gray circles represent locations of infusion tips.

behavior, and memory was evaluated by measuring the time spent freezing during the tone presentation, using Freeze View software (Actimetrics). Freezing was defined as immobilization with the exception of respiration (Blanchard and Blanchard, 1969). Pre-CS freezing was scored during the $30 \mathrm{~s}$ preceding the tone.

Histology and subcellular fractionation. For experiments not requiring molecular analysis, rats received an overdose of anesthetic and were decapitated. The brains were then removed and placed in a $20 \%$ sucroseformaline solution for $48 \mathrm{~h}$. Coronal sections of the brains were then sliced $(50 \mu \mathrm{m})$ using a cryostat (Microm Instrumentations) to verify the accuracy of cannula placements. Only rats with accurate placements were used for analysis (Fig. 1). For experiments requiring Western blots, rats were anesthetized with isoflurane immediately after memory retrieval and were decapitated, and their brains removed and frozen on dry ice. The brains were kept at $-80^{\circ} \mathrm{C}$ until further use. The amygdala was dissected from each frozen brain in the cryostat using a neuro punch (1 $\mathrm{mm}$; Fine Science Tools) and homogenized in ice-cold Tris- $\mathrm{HCl}$ buffer (30 mM, pH 7.4) containing 4 mm EDTA, 1 mm EGTA, and a protease inhibitor cocktail (Complete; Roche). The subcellular fractionation procedure performed was described previously (Migues et al., 2010). Briefly, the amygdala homogenates were then centrifuged at $500 \times g$ for $10 \mathrm{~min}$ at $4^{\circ} \mathrm{C}$ to remove the nuclei. The supernatant was then centrifuged at $100,000 \times g($ Beckman Coulter $)$ for $1 \mathrm{~h}$ at $4^{\circ} \mathrm{C}$. The pellets were resuspended in $50 \mu \mathrm{l}$ of $0.5 \%$ Triton X-100 homogenization buffer and incubated for $20 \mathrm{~min}$ on ice, before being layered over $100 \mu \mathrm{l}$ of $1 \mathrm{M}$ sucrose solution and centrifuged at $100,000 \times g$ for $1 \mathrm{~h}$ at $4^{\circ} \mathrm{C}$. The layer remaining above the sucrose, which contained the extrasynaptic receptors, was collected, and the Triton X-100-insoluble material that sedimented 

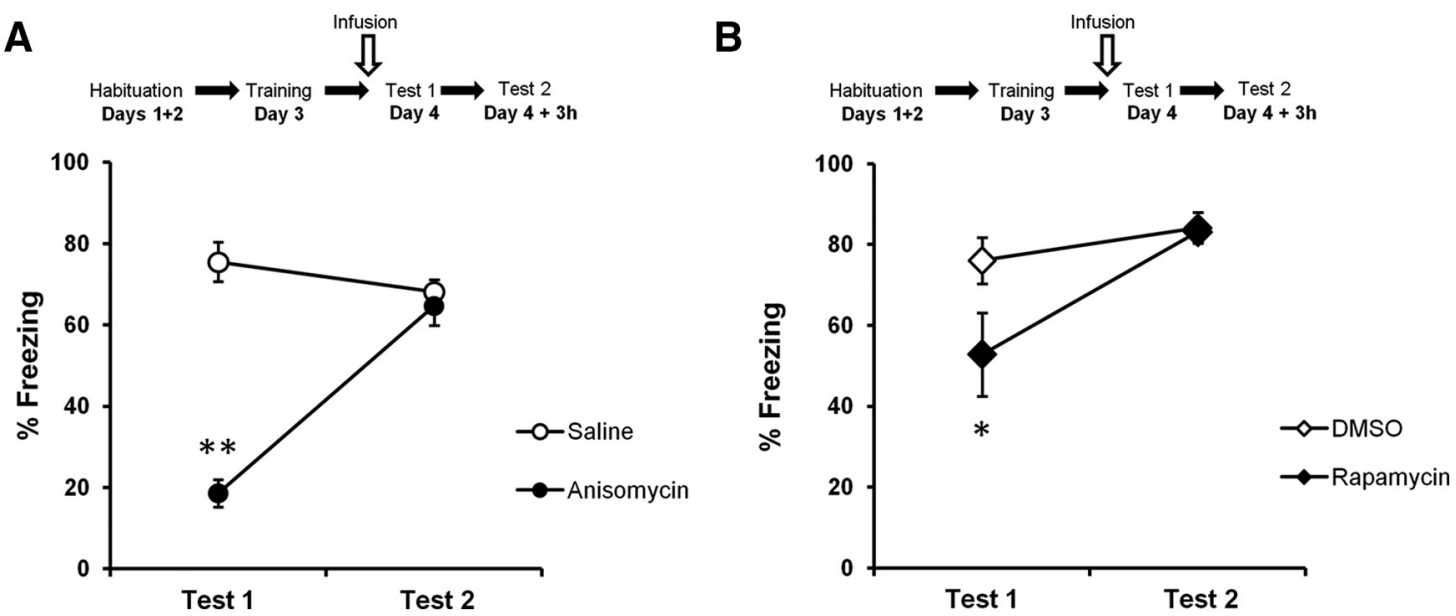

Figure 2. Two protein synthesis inhibitors transiently impair retrieval of auditory fear memories. $A, B$, Rats were trained in an auditory fear-conditioning task and received an infusion of protein synthesis inhibitor before memory retrieval Test 1. Rats showed an impairment in performance after infusions of anisomycin $(n=8 ; \boldsymbol{A})$ or rapamycin $(n=7 ; \boldsymbol{B})$ compared to vehicle-treated rats (anisomycin, $n=8$; rapamycin, $n=9$ ). Rats showed intact fear expression when tested at Test 2 . Data are expressed as the mean \pm SEM percentage of time spent freezing in response to the tone. ${ }^{*} p<0.05 ;{ }^{* *} p<0.01$.

through the sucrose layer, containing the postsynaptic densities, was resuspended in $40 \mu \mathrm{l}$ homogenization buffer and stored at $-80^{\circ} \mathrm{C}$. Total protein concentration was determined by the BCA protein assay kit (Pierce). This allowed us to quantify how much protein could be found in each sample, to determine the volume of sample necessary to load $7 \mu \mathrm{g}$ of protein into the Western blot gels [10 $\mu \mathrm{g}$ in the case of phosphorylated Ser845 (phospho-Ser845)]. All loaded samples therefore contained the same amount of protein.

Western blots. The procedure was identical to that used in previous work (Migues et al., 2010). Western blots were performed with 7.5\% SDS-PAGE. The proteins were then transferred onto nitrocellulose membranes. The membranes were incubated for $1 \mathrm{~h}$ in blocking solution [0.1\% Tween 20 and 5\% BSA in Tris-buffered saline (TBS)], rinsed with TBS, and then incubated with polyclonal GluA1 (1:1000; Millipore), phospho-Ser845-GluA1 (1:250; Millipore), or GluA2 (1:1000; Millipore) antibodies for $1 \mathrm{~h}$ or overnight (for phospho-Ser845). After TBS washes, the membranes were then incubated for $1 \mathrm{~h}$ with a secondary antibody (goat anti-rabbit horseradish peroxidase-linked IgG; ECL) and revealed with the ECL plus immunoblotting system (GE Healthcare). The membranes were then scanned on a Storm Laser scanner (Molecular Dynamics) and the signals quantified using image analysis software (ImageQuant; GE Healthcare). The raw values obtained were then normalized to vehicles, giving a relative percentage value for each measure.

Statistical analyses. All data were tested for normality distribution fitting by the Shapiro-Wilk $W$ test and for homogeneity of variance by Levene's test. When values were normally distributed and groups had identical variance, a one-way ANOVA, considering Drug as a main factor, was performed for all behavioral experiments and for comparing levels of protein in the Western blots. When appropriate, the NewmanKeuls multiple range test was performed to run multiple comparisons. When data did not meet the above ANOVA assumptions, we used the Kruskal-Wallis analysis of ranks for multiple comparisons. A regression analysis was also performed to determine any correlation between levels of protein and behavioral performance. The significance level was taken at $p<0.05$.

\section{Results}

Amygdala infusions of two protein synthesis inhibitors transiently impair auditory fear memory retrieval

Rats were trained in an auditory fear-conditioning procedure and tested $24 \mathrm{~h}$ later. The animals received a bilateral infusion of anisomycin $(n=8)$ or vehicle $(n=8) 10$ min before memory retrieval (Test 1 ), and were tested again $3 \mathrm{~h}$ later (Test 2 ) without prior infusion. A specific impairment in memory retrieval was defined as a reduced freezing response on Test 1 but not Test 2 . Rats infused with anisomycin froze significantly less to the tone than control rats on Test $1\left(F_{(1,14)}=94.8, p<0.0001\right.$; post hoc test, $p<0.05$; Fig. $2 A)$. This was no longer the case on Test $2(p>0.05)$.

Anisomycin inhibits protein synthesis at the level of translation by inhibiting peptidyl transferase activity and has several undesirable nonspecific effects such as kinase activation, alteration of neurotransmitter levels, and apoptosis (Davis and Squire, 1984; Morris et al., 2006; Rudy, 2008). We therefore repeated the experiment with another PSI, rapamycin, which acts specifically on the mammalian target of rapamycin (mTOR) activity, inhibiting its downstream signaling, which modulates translation (Raught et al., 2001; Takei et al., 2004). Rapamycin $(n=7)$ significantly decreased freezing on Test $1\left(F_{(1,14)}=4.35, p<0.05\right)$ compared to control rats $(n=9$; Fig. $2 B)$. On Test 2, no significant differences in performance were observed between the two groups $\left(F_{(1,14)}=0.045, p>0.05\right)$. These data confirmed the results obtained with anisomycin, indicating that protein synthesis is required for memory retrieval. As the memory impairment in Test 1 was no longer present at Test 2, this suggests that protein synthesis inhibition specifically affected memory retrieval and not memory storage. The similar results obtained with two PSIs acting through distinct mechanisms also support a specific impairment of memory retrieval due to protein synthesis inhibition. Even though we observed a stronger memory impairment with anisomycin, most likely because it inhibits $70-95 \%$ of protein synthesis (Parsons et al., 2006; King et al., 2008) instead of 10 $15 \%$ for rapamycin, we chose to continue using rapamycin for the subsequent experiments because less nonspecific effects have been reported for it.

Due to the rapid effect of rapamycin on memory retrieval, we hypothesized that the putative proteins involved must be translated locally at the synapses, with a fast turnover rate (Job and Eberwine, 2001). As the time between CS onset and behavioral expression of the memory is very short (a few seconds at most), this suggests that the specific synapses involved in the memory trace continually synthesize proteins necessary for memory retrieval to occur. This also suggests a possible implication of activity-induced AMPAR trafficking, as AMPAR activation in the 
amygdala during memory retrieval is known to be necessary for the behavioral expression of the conditioned response (Ben Mamou et al., 2006). Based on these results, we hypothesized that ongoing protein synthesis is crucial just before a memory is retrieved to maintain pools of proteins necessary for memory retrieval. These proteins could be involved in the activityinduced trafficking of AMPARs to the PSD. Indeed, once memory retrieval is engaged (here by presentation of the CS), NMDARs would be activated and lead to AMPAR trafficking. AMPARs would be trafficked out of the PSD and would have to be replaced for the retrieval process to be completed. In this case, we postulated that a PSI such as rapamycin would prevent the replacement of these critical proteins and lead to a reduction in synaptic AMPARs during memory retrieval (see Fig. 10A,B), which would be manifested at the behavioral level as an impairment in the conditioned response (freezing).

\section{Inhibiting NMDAR activity prevents the impairment caused by rapamycin}

The posited activity-induced receptor trafficking mechanisms described above are thought to be dependent on NMDAR activity (Passafaro et al., 2001). An NMDAR antagonist should have no effect on memory retrieval, as it would prevent the trafficking of AMPARs in and out of the PSD and thus leave the total number of receptors at the PSD unchanged (see Fig. 10C). We therefore hypothesized that an NMDAR antagonist should prevent the rapamycin-induced memory impairment. Indeed, although the number of newly synthesized proteins required for memory retrieval would be reduced with rapamycin, receptor trafficking would not be engaged, thereby maintaining a stable number of AMPARs at the PSD (see Fig. 10D). As a consequence, there would be no memory impairment. Ifenprodil, a selective NR2Bcontaining NMDAR inhibitor, has been shown to have no effect on performance when infused just before memory retrieval (Ben Mamou et al., 2006). We therefore infused rats $10 \mathrm{~min}$ before memory retrieval with either rapamycin $(n=12)$, ifenprodil $(n=$ $8)$, a mixture of ifenprodil and rapamycin $(n=8)$, or vehicle $(n=$ 11). The rats were tested again $3 \mathrm{~h}$ later without prior infusion. Rapamycin significantly decreased freezing performances compared to all other groups on Test $1\left(H_{(3, N=39)}=19.2, p<0.001\right.$; post hoc test, $p<0.05$ for all comparisons; Fig. 3). Furthermore, there was no effect of ifenprodil on memory retrieval, and no significant differences were observed between the vehicle, ifenprodil alone, and ifenprodil-rapamycin groups $(p>0.05$ for all comparisons). No significant differences were observed between groups on Test $2\left(F_{(3,35)}=0.22, p>0.05\right)$. Ifenprodil thereby prevented the impairment caused by rapamycin alone, which is consistent with the hypothesis of NMDAR activity-induced receptor trafficking being involved in memory retrieval.

\section{Inhibiting endocytosis of GluA2-containing AMPARs prevents the impairment caused by rapamycin}

If the rapamycin-induced impairment is due to a reduction in the pool of proteins required for memory retrieval and necessary to replace AMPARs at the PSD, then the strongest test for this hypothesis would be a tool that blocks only activity-dependent endocytosis. In this case, the rapamycin-induced impairment should be prevented (see Fig. 10E,F), just as observed with the NMDAR antagonist. We used GluA2 3 , a synthetic peptide derived from the GluA2 carboxy tail of AMPARs, which acts as a selective endocytosis inhibitor of GluA2-containing AMPARs (Kim et al., 2007; Migues et al., 2010). GluA2 3 Y has been reported not to have any effects on behavior when infused before memory

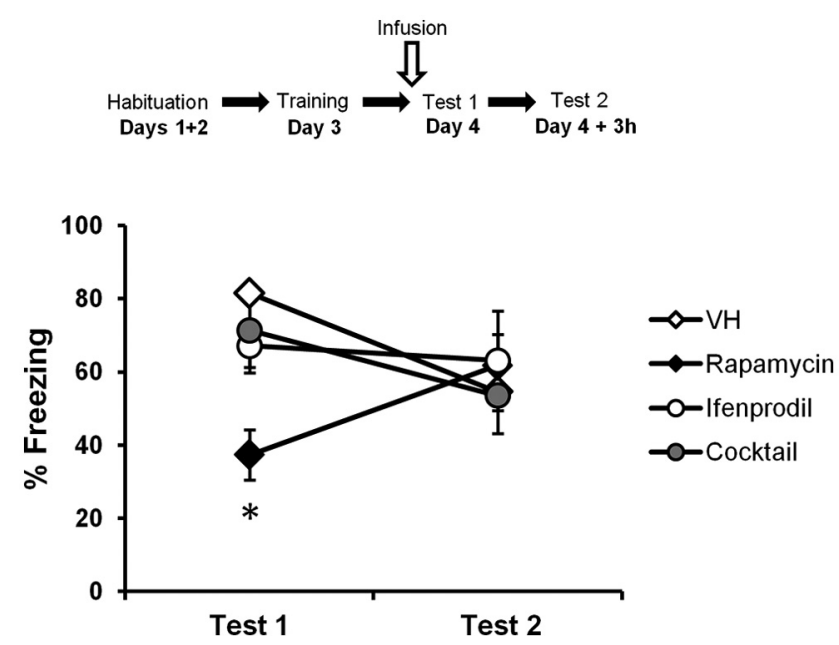

Figure 3. Inhibiting NMDAR activity prevents the impairment caused by rapamycin. Rats were trained in an auditory fear-conditioning task and received an infusion of ifenprodil alone $(n=8)$, vehicle $(\mathrm{VH} ; n=11)$, rapamycin alone $(n=12)$, or a mixture of rapamycin and ifenprodil (Cocktail; $n=8$ ) before Test 1. Rats infused with the cocktail were not impaired in performance, as opposed to rats infused with rapamycin only. Rats showed intact fear expression when tested at Test 2. Data are expressed as the mean \pm SEM percentage of time spent freezing in response to the tone. ${ }^{*} p<0.05$.
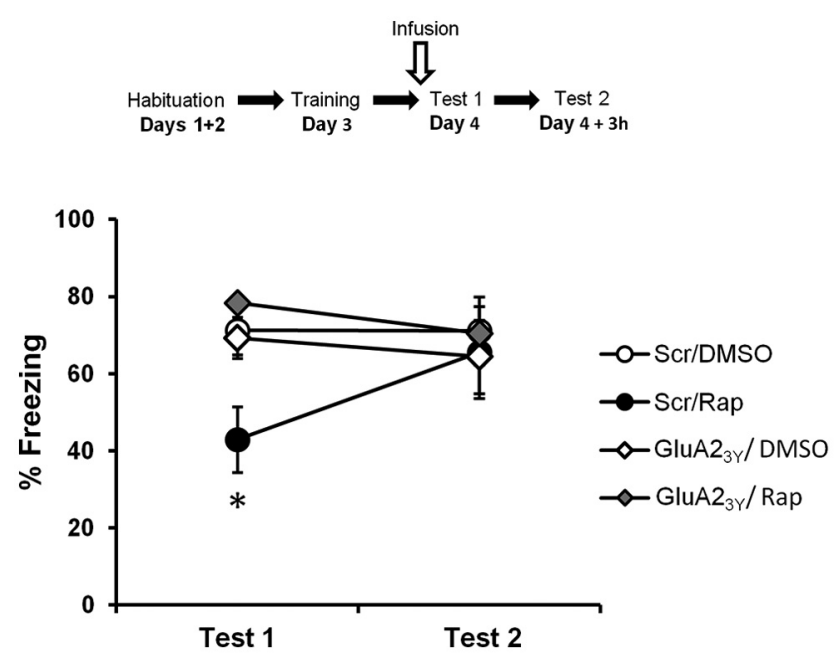

Figure 4. Inhibiting endocytosis of GluA2-containing AMPARs prevents the impairment caused by rapamycin. Rats were trained in an auditory fear-conditioning task and received an infusion of $\mathrm{GluA2}_{3 \gamma}$ and rapamycin (GluA2 ${ }_{3 \gamma} /$ Rap; $\left.n=8\right)$, scrambled-GluA2 ${ }_{3 \mathrm{Y}}$ and rapamycin (Scr/Rap; $n=8$ ), GluA2 ${ }_{3 y}$ and DMSO (GluA2 $2_{3 \gamma} /$ DMSO $n=8$ ), or vehicle (Scr/DMSO; $n=12$ ). Rats infused with both $\mathrm{GluA2}_{3 \mathrm{Y}}$ and rapamycin were not impaired in performance, as opposed to rats infused with rapamycin only. Rats showed intact fear expression when tested at Test 2. Data are expressed as the mean \pm SEM percentage of time spent freezing in response to the tone. ${ }^{*} p<0.05$.

retrieval (Hong et al., 2013). Rats therefore received two infusions: one of GluA $2_{3 \mathrm{Y}}$ or its scrambled peptide $1 \mathrm{~h}$ before memory retrieval and one of rapamycin or $80 \%$ DMSO 10 min before memory retrieval (scrambled/DMSO, $n=12$; scrambled/rapamycin, $n=8$; GluA2 ${ }_{3 \mathrm{Y}} / \mathrm{DMSO}, n=8$; GluA2 $2_{3 \mathrm{Y}} /$ rapamycin, $n=$ $8)$. They were tested again $3 \mathrm{~h}$ later, without prior infusion. Rats infused with the scrambled peptide and rapamycin froze significantly less than rats of all other groups (Fig. $4 ; F_{(3,32)}=4.61, p<$ 0.01 ; post hoc test, $p<0.05$ for all comparisons). GluA2 $2_{3 \mathrm{Y}}$ on its own had no effect on memory retrieval, as performances were equivalent to those of the vehicle group $(p>0.05)$. Furthermore, 
A

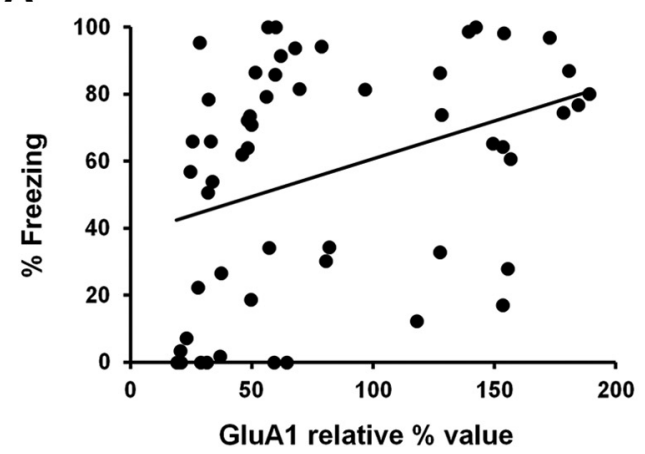

C

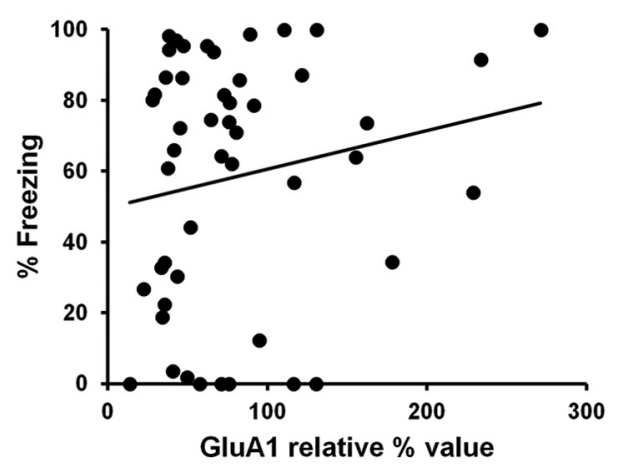

B

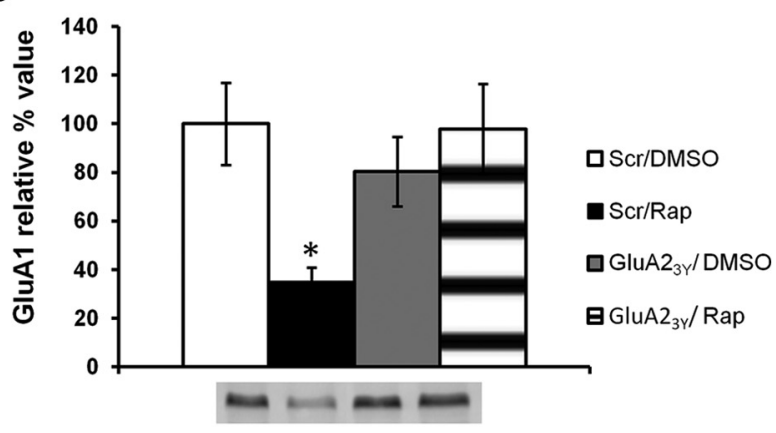

D

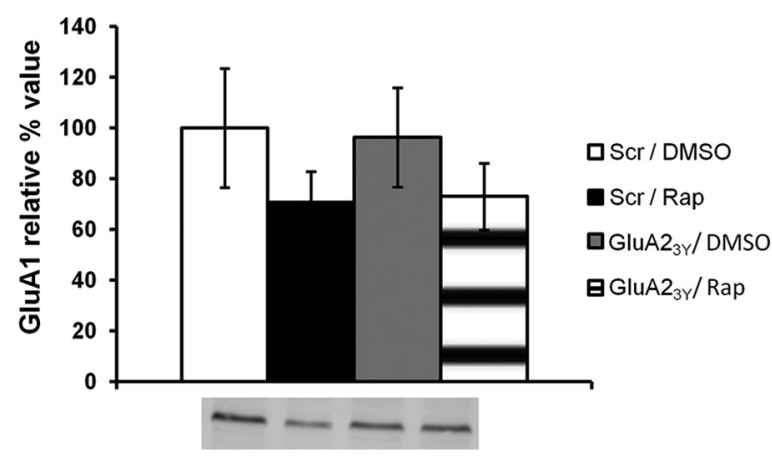

Figure 5. Infusion of rapamycin decreases levels of GluA1 at the PSD, but not at extrasynaptic sites. Rats were trained in an auditory fear-conditioning task and received an infusion of GluR2 $2_{3 \gamma}$ and

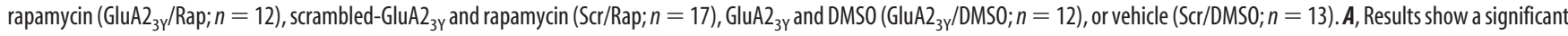
positive correlation between the percentage of time spent freezing in the memory retrieval test and levels of GluA1 at the PSD. $\boldsymbol{B}$, Rats infused with rapamycin showed significantly lower GluA1 levels than all other groups. $\boldsymbol{C}, \boldsymbol{D}$, No significant correlation $(\boldsymbol{C})$ or significant differences in GluA1 levels $(\boldsymbol{D})$ were found at extrasynaptic sites. Levels of $G$ luA1 are expressed as relative percentage values of the vehicle group \pm SEM. ${ }^{*} p<0.05$.

there were no significant differences between these two latter groups and the group of rats receiving both $\mathrm{GluA} 2_{3 \mathrm{Y}}$ and rapamycin ( $p>0.05$ for both), showing that GluA2 $2_{3 Y}$ prevented the impairment effect caused by rapamycin alone. Last, no significant differences were observed between groups on Test $2\left(F_{(3,32)}=\right.$ $0.186, p>0.05)$. These results seem to confirm the importance of trafficking of newly synthesized proteins at the time of memory retrieval.

Infusion of rapamycin decreases the levels of GluA1 at the PSD, but not at extrasynaptic sites

NMDAR activity-mediated AMPAR trafficking primarily involves GluA1/GluA2 subunits (Passafaro et al., 2001). We hypothesized that if protein synthesis is indeed required to replenish AMPARs at the PSD, then infusion of rapamycin should lead to a decrease in the levels of GluA1 at the PSD (see Fig. $10 B)$. This decrease should also be prevented by an infusion of GluA2 $2_{3 Y}$ before rapamycin (see Fig. $10 F$ ). The previous experiment with GluA2 3 was hence repeated (scrambled/DMSO, $n=$ 13; scrambled/rapamycin, $n=17$; GluA2 ${ }_{3 Y} / \mathrm{DMSO}, n=12$; GluA2 $2_{3 Y}$ /rapamycin, $n=12$ ), but animals were killed immediately after Test 1 to perform biochemical analyses. Freezing performance was significantly correlated to relative GluA1 levels at the PSD ( $r=0.35, p<0.01$; Fig. $5 A)$. Moreover, rats that were impaired during memory retrieval after infusion of rapamycin had significantly lower GluA1 levels than all other groups of rats that showed no impairment in performance $\left(H_{(3, N=40)}=13.5\right.$, $p<0.01$; post hoc test, $p<0.05$ for all comparisons; Fig. $5 B)$. The other groups had similar levels of GluA1 subunits at the PSD ( $p$ ost hoc test, $p>0.05$ for all comparisons). This contrasted with extrasynaptic GluA1 levels, which showed no significant correlation with performance $(r=0.19, p>0.05$; Fig. $5 C)$. No significant differences in extrasynaptic GluA1 levels were found between groups $\left(F_{(3,48)}=0.938, p>0.05\right.$; Fig. $\left.5 D\right)$. The data therefore suggest that the behavioral impairment observed after infusion of rapamycin is due to a decrease in GluA1 levels at the PSD. To make sure the behavioral impairment caused by this decrease in PSD GluA1 levels is due to a specific effect on memory retrieval and not to a more global effect on behavior, we analyzed levels of pre-CS freezing in the $30 \mathrm{~s}$ preceding the CS presentation. Pre-CS freezing (percentage of time spent freezing in the $30 \mathrm{~s}$ preceding the CS) was equivalent in all groups (scrambled/ DMSO, $19.76 \pm 6.01 \%$; scrambled/rapamycin, $30.07 \pm 8.22 \%$; GluA2 $_{3 Y} /$ DMSO, $16.29 \pm 7.09 \%$; GluA2 ${ }_{3 Y} /$ rapamycin, $19.02 \pm$ $10.38 \% ; F_{(3,33)}=0.661, p>0.05$; data not shown), indicating that the decrease in PSD GluA1 levels specifically impacts memory retrieval.

\section{Infusion of rapamycin does not affect levels of GluA2 at the} PSD or at extrasynaptic sites

As NMDAR activity-mediated AMPAR trafficking requires GluA1 and GluA2 subunit-containing receptors, GluA2 levels were also measured to assess specificity of the effect. Unlike for GluA1, no correlation between levels of GluA2 and freezing performance was observed at the PSD (Fig. $6 A ; r=0.22, p>0.05$ ), and no significant differences were found between groups (Fig. 
A

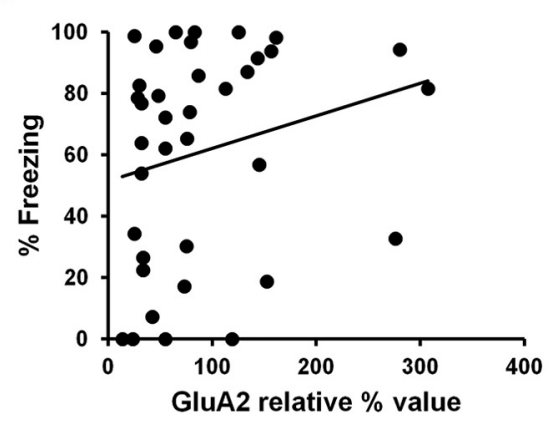

C

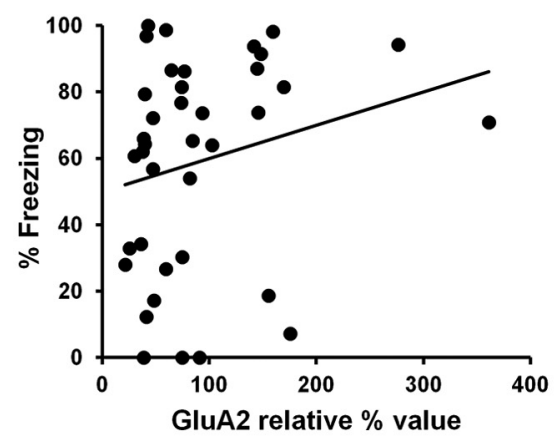

B
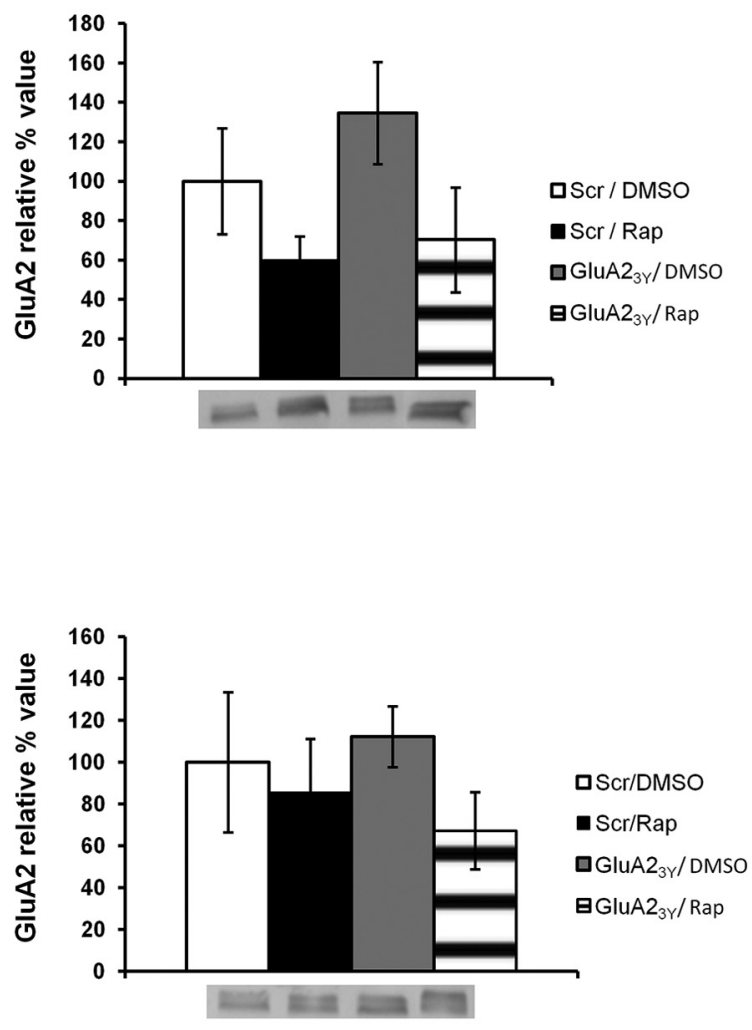

Figure 6. Infusion of rapamycin does not affect GluA2 levels at the PSD or at extrasynaptic sites. Rats were trained in an auditory fear-conditioning task and received an infusion of GluA2 ${ }_{3 \gamma}$ and rapamycin (GluA2 $2_{3 \gamma} /$ Rap; $n=12$ ), scrambled-GluA2 ${ }_{3 \gamma}$ and rapamycin (Scr/Rap; $\left.n=17\right), G l u A 2_{3 \gamma}$ and DMSO (GluA2 2 /DMSO; $\left.n=12\right)$, or vehicle (Scr/DMS0; $\left.n=13\right)$. $A, C$, Results show no significant correlation between the percentage of time spent freezing in the memory retrieval test and levels of GluA2 at the PSD $(\boldsymbol{A})$ or extrasynaptic sites $(\boldsymbol{C}) . \boldsymbol{B}, \boldsymbol{D}$, GluA2 levels were equivalent in all groups at the PSD $(\boldsymbol{B})$ and at extrasynaptic sites $(\boldsymbol{D})$. Levels of GluA2 are expressed as relative percentage values of the vehicle group \pm SEM.

$\left.6 B ; F_{(3,33)}=2.11, p>0.05\right)$. Similar results were obtained for extrasynaptic levels of GluA2 (Fig. $6 C, D$; correlation, $r=0.19$, $p>0.05$; ANOVA, $\left.F_{(3,34)}=0.67, p>0.05\right)$. As a result, the effect seems to be specific to the trafficking of GluA1-containing AMPARs to the PSD.

Infusion of rapamycin does not affect phosphorylated Ser845 levels at the PSD or at extrasynaptic sites

Ser845 is a site on AMPARs that has been shown to facilitate the insertion of AMPARs at the PSD (Ehlers, 2000; Lee et al., 2000). Consequently, it is possible that rapamycin could affect phosphorylated levels of Ser845. However, no correlation between levels of phospho-Ser845 and freezing was observed (PSD, $r=$ $0.18, p>0.05$; extrasynaptic, $r=0.051, p>0.05$; Fig. $7 A-D)$, and no significant differences were found between groups (PSD, $H_{(3, N=28)}=4.81, p>0.05$; extrasynaptic: $F_{(3,27)}=1.67, p>$ $0.05)$. This suggests rapamycin did not affect phosphorylated levels of Ser845. Nevertheless, it is possible that the methods used did not permit detection of small changes in phosphorylation levels, especially since the behavioral impairment observed after rapamycin is not as severe as with anisomycin. However, because no correlation was observed between levels of freezing and phosphorylated Ser845 levels, it is also likely that the proteins synthesized for retrieval simply do not affect Ser845 and its interactions.

Rapamycin transiently affects levels of GluA1 at the PSD

Rapamycin was shown to have a transient effect on behavior (Fig. $2 B)$. To verify whether this is also the case at the molecular level, we repeated the experiment with two groups (rapamycin and
DMSO) and killed the animals immediately after Test 2. No significant differences in PSD GluAl levels were found between groups (ANOVA, $F_{(1.25)}=0.17, p>0.05$; Fig. $8 A$ ). These results therefore confirm rapamycin's effects on GluA1 levels are transient.

Rapamycin does not affect levels of GluA1 at the PSD in the absence of memory retrieval

As NMDAR activity-mediated AMPAR trafficking should not be engaged in the absence of memory retrieval, we hypothesized that rapamycin would have no effect on GluA1 PSD levels if memory retrieval did not take place. Without memory retrieval, AMPARs should not be trafficked out of the PSD, and there should be no decrease in GluA1 PSD levels. To assess whether the rapamycininduced effects were dependent on memory retrieval, we therefore repeated the training procedure and infused animals with rapamycin $(n=8)$ or DMSO $(n=8) 24 \mathrm{~h}$ after training. The animals were not tested for memory retrieval, and instead were killed 13 min after infusion (mimicking the infusion-test delay and the duration of testing) and the brains collected for biochemical analysis. No significant difference in GluA1 levels at the PSD was found between groups (ANOVA, $F_{(1,14)}=0.53, p>0.05$; Fig. $8 B)$. This confirms that rapamycin has an effect on GluA1 PSD levels only when memory retrieval, and thus NMDAR-mediated AMPAR trafficking, is engaged.

\section{Memory retrieval does not increase PSD GluA1 levels}

Our results suggest that stable levels of GluA1 at the PSD are required for successful memory retrieval. Rapamycin would de- 
A

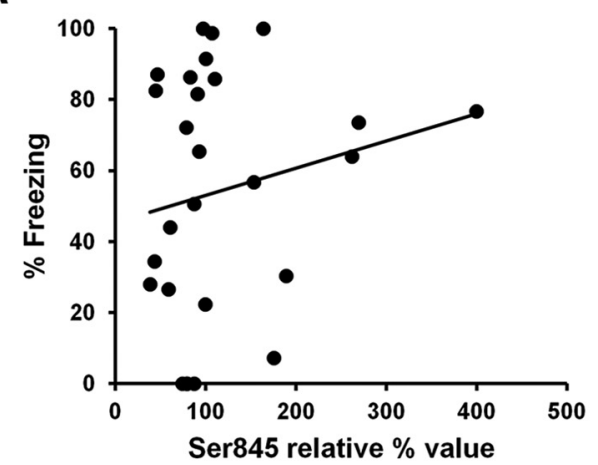

C

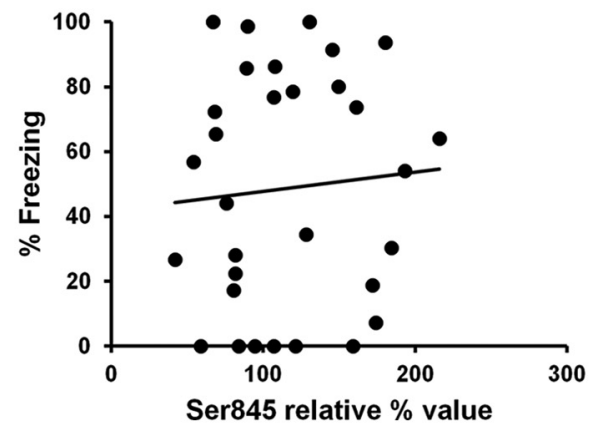

B

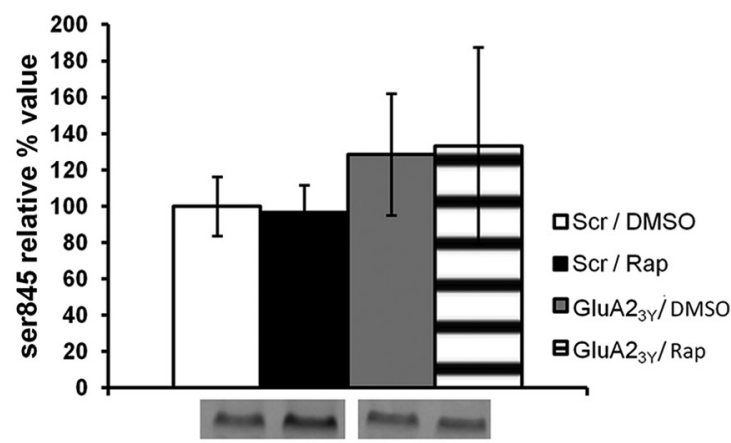

D

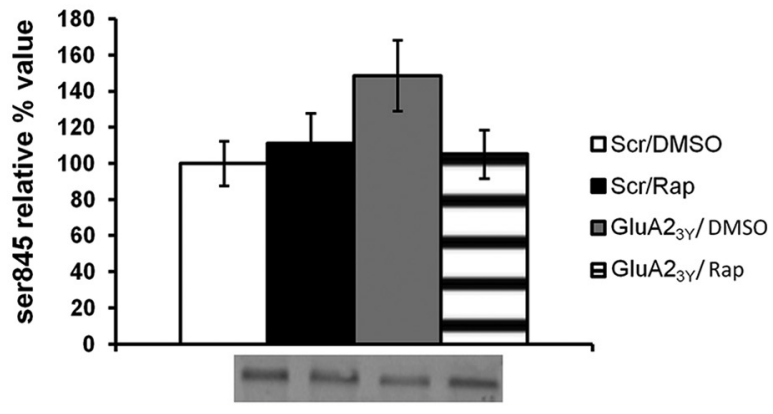

Figure 7. Infusion of rapamycin does not affect phosphorylated levels of Ser845 at the PSD or at extrasynaptic sites. Rats were trained in an auditory fear-conditioning task and received an

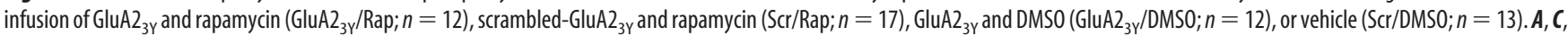
Results show no significant correlation between the percentage of time spent freezing in the retrieval test and phosphorylated levels of Ser845 at the PSD $(\boldsymbol{A})$ or extrasynaptic sites $(\boldsymbol{C})$. $\boldsymbol{B}, \boldsymbol{D}$, Phosphorylated levels of Ser845 were equivalent in all groups at the PSD $(\boldsymbol{B})$ and at extrasynaptic sites $(\boldsymbol{D})$. Separate Western blot pictures in $\boldsymbol{B}$ come from the same gel. Levels of Ser845 are expressed as relative percentage values of the vehicle group \pm SEM.

A

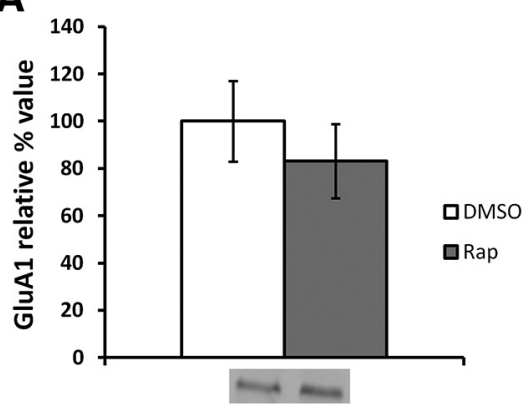

B

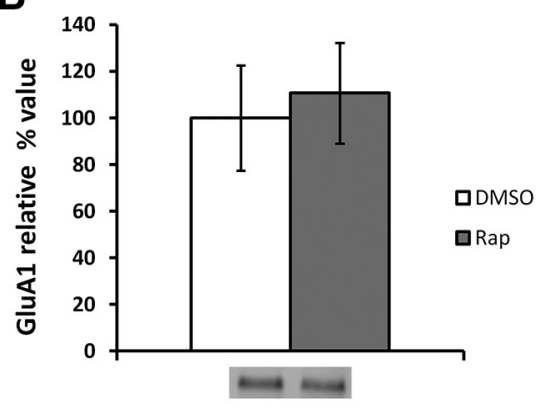

Figure 8. Infusion of rapamycin has transient effects on PSD GluA1 levels and has no effect in the absence of memory retrieval. Rats were trained in an auditory fear-conditioning task and received an infusion of rapamycin or DMSO. $\boldsymbol{A}$, When tested $3 \mathrm{~h}$ later, the groups showed no significant differences in PSD levels of GluA1 (rapamycin, $n=14$; DMSO, $n=13$ ). $\boldsymbol{B}$, When no memory retrieval takes place, no significant differences in PSD GluA1 levels are observed (rapamycin, $n=8 ;$ DMSO, $n=8$ ). Levels of GluA1 are expressed as relative percentage values of the vehicle group \pm SEM.

crease the pool of synaptic proteins necessary to replace GluA1 subunits at the PSD, and thereby lead to a behavioral impairment. However, there remains the possibility that rapamycin could cause a retrieval impairment by preventing an increase in PSD GluA1 levels that naturally occurs during retrieval. To determine whether this is the case, we normalized the previously obtained relative GluAl control values (Fig. 5B, retrieval-DMSO condition) to the control values obtained in the absence of memory retrieval (Fig. $8 B$, no retrieval-DMSO condition). No significant difference was found between groups $\left(F_{(1,18)}=0.0205, p>\right.$ 0.05 ; Fig. 9), suggesting that retrieval does not induce an increase in PSD GluA1 levels. This reinforces our hypothesis that memory retrieval requires stable levels of GluA1 at the PSD.

\section{Discussion}

This study shows that ongoing protein synthesis in the synapses mediating a memory trace is required to enable auditory fear memory retrieval. Furthermore, we demonstrate that stable levels of GluA1-containing AMPARs at the PSD are necessary to ensure successful memory retrieval, and we show that this is achieved through NMDAR activity-mediated AMPAR trafficking.

Both anisomycin and rapamycin impaired memory retrieval when infused in the amygdala $10 \mathrm{~min}$ before the memory retrieval test, without affecting pre-CS freezing. Additionally, this impairment was no longer apparent on Test 2, which suggests the drugs did not cause damage or long-term dysfunction to the tissue and demonstrates that the PSIs selectively affected memory retrieval and not memory storage. Although we cannot totally exclude the possibility that rapamycin might affect other molecular targets, as mTOR is also involved in pyrimidine synthesis (Ben-Sahra et al., 2013) and ribosome biogenesis (Iadevaia et al., 2012), we nonetheless obtained similar results with two PSIs that exert their effects through distinct mechanisms, thereby providing strong evidence that the observed behavioral impairments were specific 


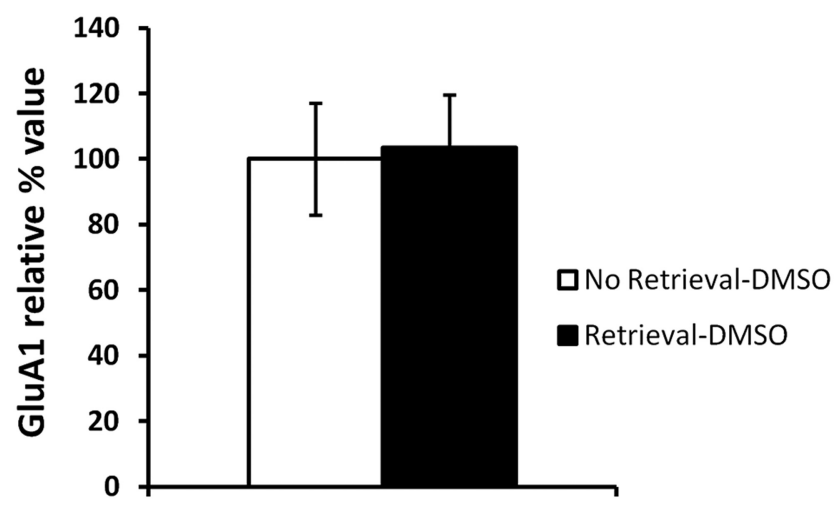

Figure 9. Memory retrieval does not increase GluA1 levels at the PSD. No significant differences were found between PSD levels of GluA1 in the No Retrieval-DMSO $(n=8)$ and RetrievalDMSO $(n=12)$ groups. Error bars indicate SEM.

to protein synthesis inhibition. Interestingly, it was also shown that mTOR is present at the synapse to modulate synthesis of locally translated proteins and that it is necessary during consolidation to increase levels of GluA1-containing AMPARs at the synapse (Slipczuk et al., 2009). A similar mechanism may thus occur for memory retrieval. Although the role of de novo protein synthesis in consolidation and reconsolidation has largely been described, its role in memory retrieval has rarely been addressed directly. The early studies on protein synthesis typically investigated the effects of PSIs on memory retrieval when injected before or at several time-points after training, but PSIs were rarely infused just before the memory retrieval test (Daniels, 1971; Davis and Squire, 1984). More recently, rapamycin was found to impair contextual fear memory reconsolidation when infused in the dorsal hippocampus $30 \mathrm{~min}$ before reactivation and tested $24 \mathrm{~h}$ later (Gafford et al., 2011). Memory expression at reactivation, however, was not affected. Similar results were obtained with auditory fear conditioning when rapamycin was infused in the amygdala $15 \mathrm{~min}$ before reactivation (Jobim et al., 2012). The difference in tasks, dosage, infusion delays, and brain structures studied could explain discrepancies with our data. For example, a longer delay would allow time for some newly synthesized proteins to be trafficked to the PSD, unlike with our 10 min delay. It is also likely that proteins required for reconsolidation and memory retrieval differ. Indeed, reconsolidation seems to depend on retrieval-induced endocytosis of GluA2-containing AMPARs (Rao-Ruiz et al., 2011), whereas, as suggested in this study, successful memory retrieval depends on a stable level of GluA1-containing AMPARs at the PSD.

The fact that a very short delay (10 $\mathrm{min})$ between PSI infusion and the test was able to impair memory retrieval suggests that the protein(s) affected must have a high turnover rate at the synapse, and thus that AMPAR trafficking was involved. Indeed, AMPARs remain at the neuronal surface for only several minutes, and lateral diffusion between extrasynaptic and synaptic sites can occur within seconds (Bats et al., 2007; Choquet, 2010). This suggests that ongoing protein synthesis was occurring at the synapse to maintain stable PSD levels of GluA1-containing AMPARs and thus enable successful memory retrieval at any time. Fear conditioning in rats leads to an increase in GluA1 surface and synaptic expression in the amygdala, this increase being dependent on NMDAR activation (Yeh et al., 2006). Furthermore, it was observed that total levels of GluA1 mRNA in the amygdala remained stable after fear conditioning, suggesting that local de novo protein synthesis occurred as a response to learning, to traf- fic AMPARs to the synapse (Yeh et al., 2006). A similar phenomenon could therefore happen for memory retrieval. Our results tend to support this, as ifenprodil, by blocking all trafficking, prevented the rapamycin-induced impairment. This suggests that when all trafficking in and out of the PSD is blocked, protein synthesis is not required for memory retrieval to occur. Indeed, even though the newly synthesized proteins are not trafficked to the PSD, memory is expressed normally. This ongoing protein synthesis may therefore be important before memory retrieval to replenish proteins at the PSD during memory retrieval, via NMDAR activity-mediated AMPAR trafficking. These data are consistent with previous work showing that NMDAR antagonists could reduce AMPAR endocytosis, thereby maintaining a stable level of GluA1-containing AMPARs at the synapse (Ehlers, 2000). To confirm this, we infused GluA2 $2_{3 Y}$ before rapamycin, thereby selectively blocking the decrease of AMPAR levels at the PSD without affecting their basal surface expression (Kim et al., 2007; Migues et al., 2010). This also prevented the memory impairment, confirming that protein synthesis is not required for memory retrieval when AMPARs are no longer trafficked out of the PSD, and consolidating the idea that ongoing protein synthesis is needed to maintain stable levels of GluA1-containing receptors at the PSD. It also suggested that rapamycin impaired performance by causing a decrease in PSD GluA1 levels, which we did observe. This effect was prevented by GluA2 $2_{3 \mathrm{Y}}$ infusion, only occurred if memory retrieval was engaged, and was fully reversed $3 \mathrm{~h}$ later. GluA2 $2_{3 Y}$ on its own did not affect GluA1 levels, which seems to contrast with the study by Hong et al. (2013) in which preretrieval GluA2 3 infusion changed the AMPAR rectification ratio by increasing GluA2-lacking AMPARs. However, these electrophysiological findings cannot accurately be transposed to relative numbers of receptors, and thus can hardly be compared directly to our effects on PSD GluA1 levels.

According to our results, rapamycin had no effect on extrasynaptic GluA1 and phospho-Ser845 levels. This suggests that GluA1 is not the protein affected by PS inhibition, as reduced GluA1 levels would have been expected at extrasynaptic sites as well after rapamycin infusion. Furthermore, newly synthesized AMPAR subunits take at least $20 \mathrm{~min}$ to reach the membrane (Horton and Ehlers, 2003), which does not fit the short time course of our results. It is more likely that proteins associated with trafficking GluA1 to the PSD are the ones being synthesized for memory retrieval to take place. Possible candidates could be protein kinase A (PKA) or MAPK, which are known to be necessary for memory retrieval (Szapiro et al., 2000, 2002), or CAMKII, which is associated with AMPAR trafficking (Lu et al., 2010; Nikandrova et al., 2010), though has been shown not to be necessary for memory retrieval (Szapiro et al., 2000). However, our results point to a specific effect on GluA1 subunits, as no correlation was found between the PSD or extrasynaptic levels of GluA2 and performance. GluA2 levels were a bit lower in the rapamycin group compared to the vehicle group. Nevertheless, as GluA1 subunits associate with GluA2 subunits to form the most common type of AMPAR found in activity-mediated AMPAR trafficking, it is possible that the global numbers of GluA2-containing receptors were slightly reduced as a consequence of the effects of rapamycin on GluA1 subunits. The results of our study therefore suggest that the proteins synthesized are specific to GluA1-containing AMPARs. It is therefore more likely that proteins such as Stargazin (TARP $\gamma$-2) or SAP97 would be involved, since both interact specifically with GluA1 (Malinow and Malenka, 2002; Choquet, 2010). Stargazin, for example, has been shown to interact directly with AMPARs to regulate their levels at the synapse by 
A

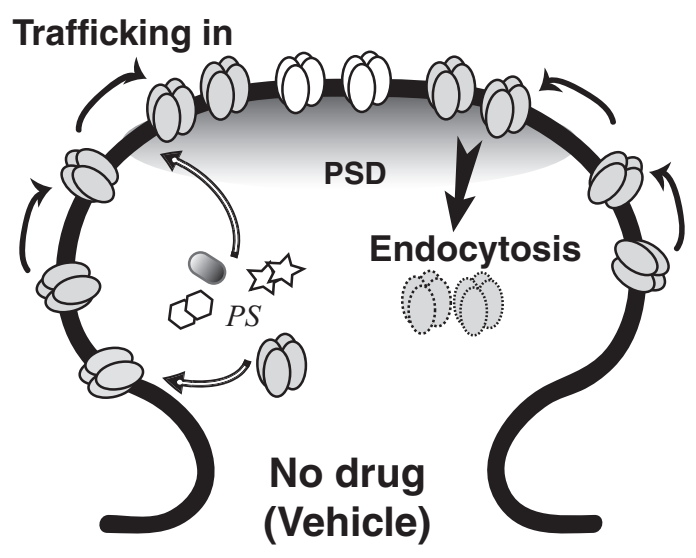

C

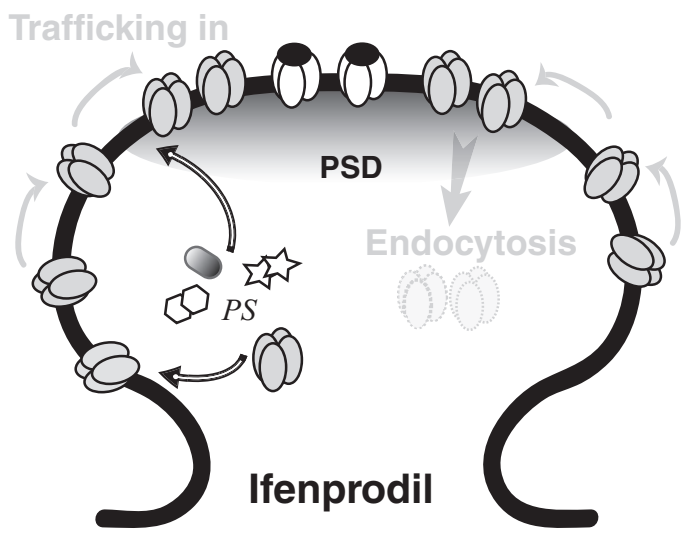

E
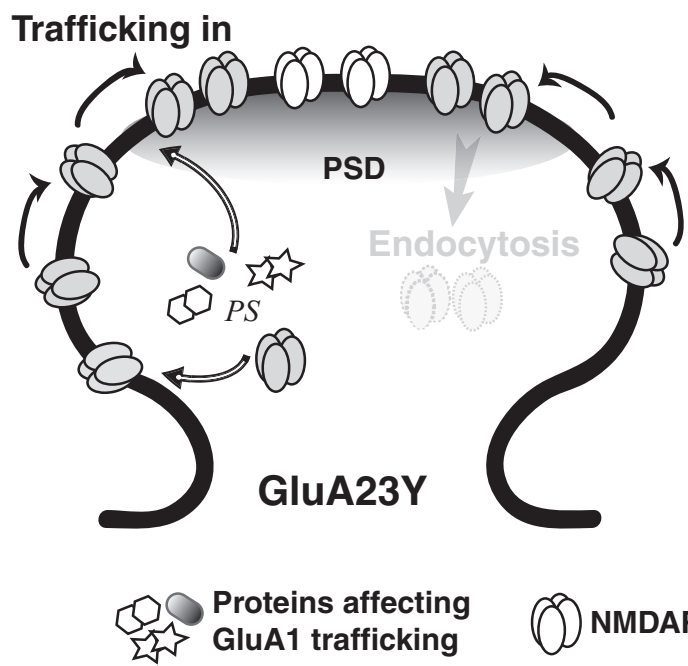

B
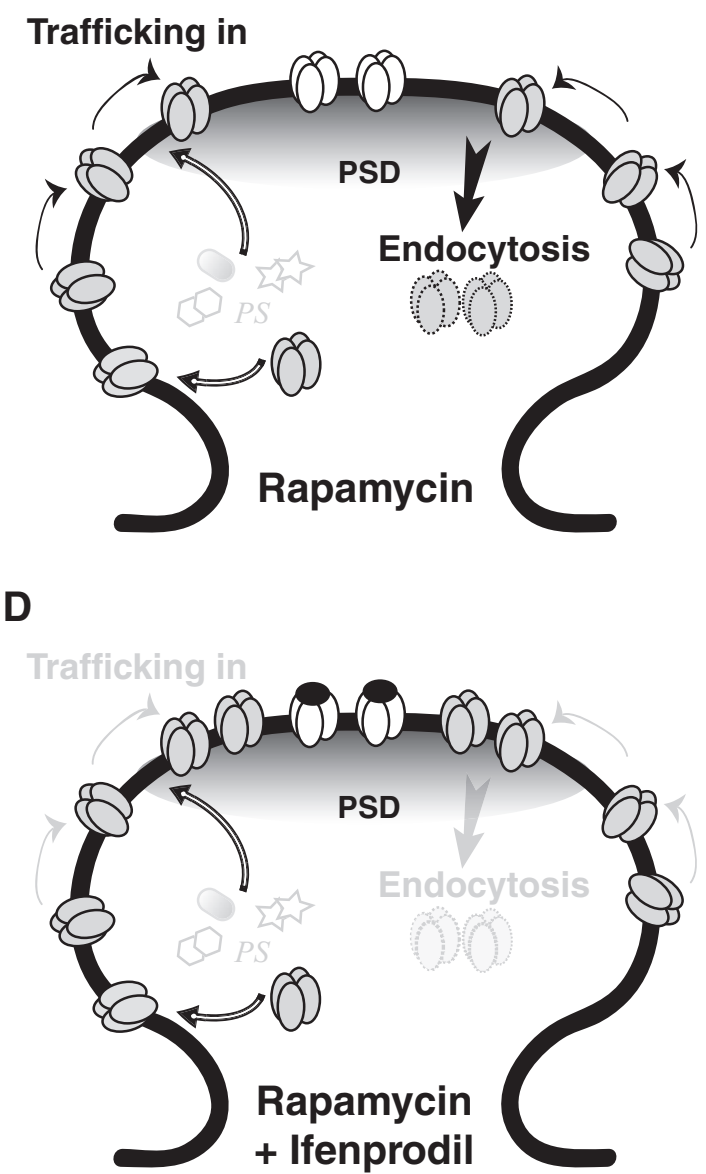

$\mathbf{F}$
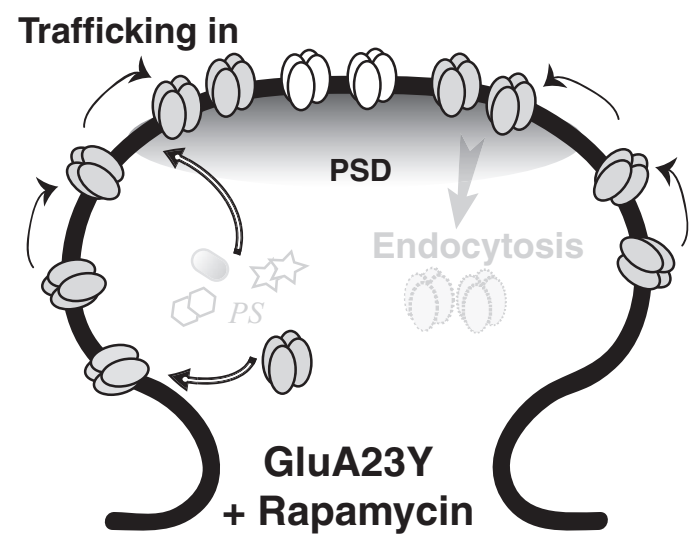

Ifenprodil
(1) GluA1-AMpar

Figure 10. Model for the mechanisms of memory retrieval. The receptors' dynamics represented in this schematic are those induced by activity-dependent AMPAR trafficking (at the time of memory retrieval); constitutive trafficking is not shown. A, During memory retrieval, NMDAR activity-mediated AMPAR trafficking is engaged. Ongoing protein synthesis (PS) occurs locally at synapses, which provides a pool of proteins necessary for memory retrieval to occur. $B$, Infusion of a PSI before memory retrieval prevents the synthesis of proteins critical for the replacement of GluA1-containing AMPARs that undergo endocytosis, causing a decrease in their levels at the PSD and leading to a memory retrieval impairment. C, Ifenprodil blocks NMDAR activity and all AMPAR trafficking. The number of GluA1-containing AMPARs in the PSD therefore remains stable, and memory retrieval occurs just as in physiological conditions. $D$, Coinfusion of ifenprodil and rapamycin prevents the memory retrieval impairment caused by rapamycin. This is because ifenprodil prevents all trafficking, including endocytosis of AMPARs. As a result, despite the lack of newly synthesized proteins being trafficked to the PSD, the number of GluA1-containing AMPARs at the PSD remains stable, and memory retrieval occurs just as in controls. $E$, Infusion of GluA2 $3 \gamma$ blocks endocytosis; GluA1-containing AMPAR levels at the PSD remain stable, and memory retrieval occurs as in physiological conditions. $F$, Infusion of GluA2 $3 \gamma$ before rapamycin prevents the memory retrieval impairment caused by rapamycin. Despite the lack of newly synthesized proteins, endocytosis is prevented, so the number of GluA1-containing AMPARs remains the same, and memory retrieval can occur just as in controls. 
facilitating targeting to the synapse (Choquet and Triller, 2003; Díaz, 2010). Indeed, during activity-dependent synaptic plasticity, PKA and NMDAR activation regulate the binding of Stargazin to PSD-95 and thus promote AMPAR trafficking (Choi et al., 2002), making Stargazin an excellent candidate.

Based on our findings, we elaborated a model for the mechanisms of memory retrieval, in which ongoing protein synthesis is required before memory retrieval to maintain stable levels of GluA1-containing receptors at the PSD during memory retrieval, through NMDAR activity-mediated AMPAR trafficking (Fig. $10 A-F)$. Further research will now be necessary to identify which proteins interacting with GluA1 are being synthesized for memory retrieval to occur and thereby allow the model to be refined. It could also be of interest to see whether our results can be extended to other memory processes requiring protein synthesis, such as consolidation and reconsolidation, and investigate whether a similar interaction between protein synthesis and NMDAR activity-mediated AMPAR trafficking could be involved. For example, it would be interesting to see in the amygdala whether PSIs could prevent consolidation or reconsolidation by affecting the synthesis of proteins necessary for GluA1containing-AMPAR trafficking to the PSD.

In conclusion, the results of this study demonstrate that memory retrieval is a dynamic process, just like learning, consolidation, reconsolidation, and memory maintenance. We show that ongoing protein synthesis and NMDAR activity-mediated AMPAR trafficking are required for fear memory retrieval. Moreover, we propose a unique model to describe the mechanisms of memory retrieval. These novel findings could have several important implications for pathologies that are caused by memory retrieval deficits such as amnesia or Alzheimer's disease. Indeed, the molecular substrates of memory retrieval could be targeted for therapies to facilitate memory expression in a number of medical conditions.

\section{References}

Abel T, Lattal KM (2001) Molecular mechanisms of memory acquisition, consolidation and retrieval. Curr Opin Neurobiol 11:180-187. CrossRef Medline

Bats C, Groc L, Choquet D (2007) The interaction between Stargazin and PSD-95 regulates AMPA receptor surface trafficking. Neuron 53:719734. CrossRef Medline

Ben-Sahra I, Howell JJ, Asara JM, Manning BD (2013) Stimulation of de novo pyrimidine synthesis by growth signaling through mTOR and S6K1. Science 339:1323-1328. CrossRef Medline

Berman RF, Kesner RP, Partlow LM (1978) Passive avoidance impairment in rats following cycloheximide injection into the amygdala. Brain Res 158:171-188. CrossRef Medline

Blanchard RJ, Blanchard DC (1969) Passive and active reactions to feareliciting stimuli. J Comp Physiol Psychol 68:129-135. CrossRef Medline

Castellucci VF, Blumenfeld H, Goelet P, Kandel ER (1989) Inhibitor of protein synthesis blocks long-term behavioral sensitization in the isolated gill-withdrawal reflex of Aplysia. J Neurobiol 20:1-9. CrossRef Medline

Choi J, Ko J, Park E, Lee JR, Yoon J, Lim S, Kim E (2002) Phosphorylation of Stargazin by protein kinase A regulates its interaction with PSD-95. J Biol Chem 277:12359-12363. CrossRef Medline

Choquet D (2010) Fast AMPAR trafficking for a high-frequency synaptic transmission. Eur J Neurosci 32:250-260. CrossRef Medline

Choquet D, Triller A (2003) The role of receptor diffusion in the organization of the postsynaptic membrane. Nat Rev Neurosci 4:251-265. CrossRef Medline

Daniels D (1971) Acquisition, storage, and recall of memory for brightness discrimination by rats following intracerebral infusion of acetoxycycloheximide. J Comp Physiol Psych 76:110-118. CrossRef

Davis HP, Squire LR (1984) Protein synthesis and memory: a review. Psychol Bull 96:518-559. CrossRef Medline
Díaz E (2010) Regulation of AMPA receptors by transmembrane accessory proteins. Eur J Neurosci 32:261-268. CrossRef Medline

Ehlers MD (2000) Reinsertion or degradation of AMPA receptors determined by activity-dependent endocytic sorting. Neuron 28:511-525. CrossRef Medline

Gafford GM, Parsons RG, Helmstetter FJ (2011) Consolidation and reconsolidation of contextual fear memory requires mammalian target of rapamycin-dependent translation in the dorsal hippocampus. Neuroscience 182:98-104. CrossRef Medline

Hall J, Thomas KL, Everitt BJ (2001) Fear memory retrieval induces CREB phosphorylation and Fos expression within the amygdala. Eur J Neurosci 13:1453-1458. CrossRef Medline

Hong I, Kim J, Kim J, Lee S, Ko HG, Nader K, Kaang BK, Tsien RW, Choi S (2013) AMPA receptor exchange underlies transient memory destabilization on retrieval. Proc Natl Acad Sci U S A 110:8218-8223. CrossRef Medline

Horton AC, Ehlers MD (2003) Dual modes of endoplasmic reticulum-toGolgi transport in dendrites revealed by live-cell imaging. J Neurosci 23:6188-6199. Medline

Iadevaia V, Huo Y, Zhang Z, Foster LJ, Proud CG (2012) Roles of the mammalian target of rapamycin, mTOR, in controlling ribosome biogenesis and protein synthesis. Biochem Soc Trans 40:168-172. CrossRef Medline

Job C, Eberwine J (2001) Localization and translation of mRNA in dentrites and axons. Nat Rev Neurosci 2:889-898. CrossRef Medline

Jobim PF, Pedroso TR, Christoff RR, Werenicz A, Maurmann N, Reolon GK, Roesler R (2012) Inhibition of mTOR by rapamycin in the amygdala or hippocampus impairs formation and reconsolidation of inhibitory avoidance memory. Neurobiol Learn Mem 97:105-112. CrossRef Medline

Kandel ER (2001) The molecular biology of memory storage: a dialogue between genes and synapses. Science 294:1030-1038. CrossRef Medline

Kim J, Lee S, Park K, Hong I, Song B, Son G, Park H, Kim WR, Park E, Choe HK, Kim H, Lee C, Sun W, Kim K, Shin KS, Choi S (2007) Amygdala depotentiation and fear extinction. Proc Natl Acad Sci U S A 104:2095520960. CrossRef Medline

King MA, Hands S, Hafiz F, Mizushima N, Tolkovsky AM, Wyttenbach A (2008) Rapamycin inhibits polyglutamine aggregation independently of autophagy by reducing protein synthesis. Mol Pharmacol 73:1052-1063. CrossRef Medline

Lee HK, Barbarosie M, Kameyama K, Bear MF, Huganir RL (2000) Regulation of distinct AMPA receptor phosphorylation sites during bidirectional synaptic plasticity. Nature 405:955-959. CrossRef Medline

Lu W, Isozaki K, Roche KW, Nicoll RA (2010) Synaptic targeting of AMPA receptors is regulated by a CaMKII site in the first intracellular loop of GluA1. Proc Natl Acad Sci U S A 107:22266-22271. CrossRef Medline

Malinow R, Malenka RC (2002) AMPA receptor trafficking and synaptic plasticity. Annu Rev Neurosci 25:103-126. CrossRef Medline

Ben Mamou C, Gamache K, Nader K (2006) NMDA receptors are critical for unleashing consolidated auditory fear memories. Nat Neurosci 9:1237-1239. CrossRef Medline

Martin SJ, Grimwood PD, Morris RG (2000) Synaptic plasticity and memory: an evaluation of the hypothesis. Annu Rev Neurosci 23:649-711. CrossRef Medline

Migues PV, Hardt O, Wu DC, Gamache K, Sacktor TC, Wang YT, Nader K (2010) PKM[zeta] maintains memories by regulating GluR2-dependent AMPA receptor trafficking. Nat Neurosci 13:630-634. CrossRef Medline

Morris RG, Inglis J, Ainge JA, Olverman HJ, Tulloch J, Dudai Y, Kelly PA (2006) Memory reconsolidation: sensitivity of spatial memory to inhibition of protein synthesis in dorsal hippocampus during encoding and retrieval. Neuron 50:479-489. CrossRef Medline

Murchison CF, Zhang XY, Zhang WP, Ouyang M, Lee A, Thomas SA (2004) A distinct role for norepinephrine in memory retrieval. Cell 117:131-143. CrossRef Medline

Nader K (2003) Memory traces unbound. Trends Neurosci 26:65-72. CrossRef Medline

Nikandrova YA, Jiao Y, Baucum AJ, Tavalin SJ, Colbran RJ (2010) Ca2+/ calmodulin-dependent protein kinase II binds to and phosphorylates a specific SAP97 splice variant to disrupt association with AKAP79/150 and modulate $\alpha$-amino-3-hydroxy-5-methyl-4-isoxazolepropionic acid-type glutamate receptor (AMPAR) activity. J Biol Chem 285:923-934. CrossRef Medline

Parsons RG, Gafford GM, Helmstetter FJ (2006) Translational control via the mammalian target of rapamycin pathway is critical for the formation and stability of long-term fear memory in amygdala neurons. J Neurosci 26:12977-12983. CrossRef Medline 
Passafaro M, Piëch V, Sheng M (2001) Subunit-specific temporal and spatial patterns of AMPA receptor exocytosis in hippocampal neurons. Nat Neurosci 4:917-926. CrossRef Medline

Rao-Ruiz P, Rotaru DC, van der Loo RJ, Mansvelder HD, Stiedl O, Smit AB, Spijker S (2011) Retrieval-specific endocytosis of GluA2-AMPARs underlies adaptive reconsolidation of contextual fear. Nat Neurosci 14: 1302-1308. CrossRef Medline

Raught B, Gingras AC, Sonenberg N (2001) The target of rapamycin (TOR) proteins. Proc Natl Acad Sci U S A 98:7037-7044. CrossRef Medline

Riedel G, Micheau J, Lam AG, Roloff EL, Martin SJ, Bridge H, de Hoz L, Poeschel B, McCulloch J, Morris RG (1999) Reversible neural inactivation reveals hippocampal participation in several memory processes. Nat Neurosci 2:898-905. CrossRef Medline

Rudy JW (2008) Is there a baby in the bathwater? Maybe: Some methodological issues for the de novo protein synthesis hypothesis. Neurobiol Learn Mem 89:219-224. CrossRef Medline

Rumpel S, LeDoux J, Zador A, Malinow R (2005) Postsynaptic receptor trafficking underlying a form of associative learning. Science 308:83-88. CrossRef Medline

Slipczuk L, Bekinschtein P, Katche C, Cammarota M, Izquierdo I, Medina JH
(2009) BDNF activates mTOR to regulate GluR1 expression required for memory formation. PLoS One 4:e6007. CrossRef Medline

Steele RJ, Morris RG (1999) Delay-dependent impairment of a matchingto-place task with chronic and intrahippocampal infusion of the NMDAantagonist D-AP5. Hippocampus 9:118-136. CrossRef Medline

Szapiro G, Izquierdo LA, Alonso M, Barros D, Paratcha G, Ardenghi P, Pereira P, Medina JH, Izquierdo I (2000) Participation of hippocampal metabotropic glutamate receptors, protein kinase A and mitogenactivated protein kinases in memory retrieval. Neuroscience 99:1-5. CrossRef Medline

Szapiro G, Galante JM, Barros DM, Levi de Stein M, Vianna MR, Izquierdo LA, Izquierdo I, Medina JH (2002) Molecular mechanisms of memory retrieval. Neurochem Res 27:1491-1498. CrossRef Medline

Takei N, Inamura N, Kawamura M, Namba H, Hara K, Yonezawa K, Nawa H (2004) Brain-derived neurotrophic factor induces mammalian target of rapamycin-dependent local activation of translation machinery and protein synthesis in neuronal dendrites. J Neurosci 24:9760-9769. CrossRef Medline

Yeh SH, Mao SC, Lin HC, Gean PW (2006) Synaptic expression of glutamate receptor after encoding of fear memory in the rat amygdala. Mol Pharmacol 69:299-308. Medline 